\title{
EDITORIAL
}

\section{Spotlight review series on multiple myeloma}

\author{
Leukemia (2009), R1-R2; doi:10.1038/leu.2009.243
}

In the last decade, we have witnessed unprecedented progress in the diagnosis and treatment of multiple myeloma. ${ }^{1,2}$ These advances, although helped by a few serendipitous observations, are associated with a major improvement in our understanding of myeloma cytogenetics and biology, and a greater realization of the role played by the bone marrow microenvironment in disease pathogenesis and progression. ${ }^{3-6}$

Myeloma evolves from an asymptomatic premalignant stage termed monoclonal gammopathy of undetermined significance (MGUS), which is prevalent in over $3 \%$ of the population above the age of 50 years. ${ }^{7}$ MGUS seems to originate as an aberrant response to antigenic stimulation mediated by aberrant Toll-like receptor (TLR) expression. ${ }^{8-10}$ Approximately $50 \%$ of MGUS is associated with primary translocations in the clonal plasma cells involving the immunoglobulin heavy chain $(\mathrm{IgH})$ locus on chromosome $14 q 32$ and various partner chromosome loci, such as 11q13 (CCND1 (cyclin D1 gene)), 4p16.3 (FGFR-3 and MMSET), 6p21 (CCND3 (cyclin D3 gene)), 16q23 (c-maf), and $20 q 11$ (mafB). ${ }^{11}$ Most of the remaining cases of MGUS are associated with hyperdiploidy (IgH nontranslocated MGUS). ${ }^{12}$

MGUS progresses to myeloma or related malignancy at the rate of $1 \%$ per year. ${ }^{13}$ The progression of MGUS to myeloma is accompanied by additional cytogenetic changes such as secondary translocations and p53 mutations, as well as alterations in the bone marrow microenvironment, including induction of angiogenesis, suppression of cell-mediated immunity, increased dickkopf 1 (DKK1) expression, increase in receptor activator of nuclear factor $\kappa B$ ligand (RANKL) expression and a reduction in the level of its decoy receptor, osteoprotegerin (OPG). ${ }^{14}$

The evolution of MGUS to myeloma is marked by familiar signs of end-organ damage, including osteolytic bone lesions, anemia, hypercalcemia and renal failure. Myeloma remains incurable, but new treatment options such as thalidomide, ${ }^{15}$ bortezomib ${ }^{16-18}$ and lenalidomide ${ }^{19,20}$ have dramatically altered the treatment of the disease, and significantly prolonged the survival of myeloma patients. ${ }^{21}$ Additional agents such as carfilzomib and pomalidomide are on the horizon. These new agents produce high rates of response, which was hitherto possible only in the context of stem cell transplantation.

Today, many investigators consider myeloma to be a heterogenous mix of cytogenetically distinct entities sharing a similar phenotype. The prognosis and response to therapy of myeloma vary greatly based on baseline cytogenetic abnormalities. $^{22-28}$ In fact, it is likely that in the future treatments will be delivered in a more individualized manner based on underlying chromosomal and gene-expression characteristics. ${ }^{29}$ To highlight and critically evaluate recent advances in the biology and treatment of myeloma, we published a special spotlight series of 14 comprehensive review articles in Leukemia. The reviews in this spotlight series cover the most important advances in the clinical and laboratory aspects of the disease in recent years and lay the directions for future myeloma research. Each review was authored by investigators who played a leading role in the advances described. The rapid pace of changes in the myeloma field has resulted in the need for revising existing diagnostic, prognostic and response criteria, as well as treatment recommendations. ${ }^{23,30}$ In this regard, the spotlight series ${ }^{31-44}$ includes consensus statements on controversial and evolving areas such as molecular classification and new laboratory tests. We are confident that the myeloma spotlight series will be a resource for all investigators in the field, as well as clinical practitioners treating myeloma, laboratory scientists in related fields and other hematologists.

\section{Conflict of interest}

The authors declare no conflict of interest.

SV Rajkumar ${ }^{1}$ and NM-B Killmann ${ }^{2}$

${ }^{1}$ Division of Hematology, Mayo Clinic, Rochester, MN, USA and ${ }^{2}$ Editor in chief for Leukemia, Leukemia Journal, Paris, France

E-mail: rajkumar.vincent@mayo.edu

\section{References}

1 Kyle RA, Rajkumar SV. Multiple myeloma. Blood 2008; 111: 2962-2972.

2 Anderson KC, Kyle RA, Rajkumar SV, Stewart AK, Weber D, Richardson P. Clinically relevant end points and new drug approvals for myeloma. Leukemia 2007; 22: 231-239.

3 Yasui H, Hideshima T, Richardson PG, Anderson KC. Novel therapeutic strategies targeting growth factor signalling cascades in multiple myeloma. Br J Haematol 2006; 132: 385-397.

4 Corre J, Mahtouk K, Attal M, Gadelorge M, Huynh A, Fleury-Cappellesso $\mathrm{S}$ et al. Bone marrow mesenchymal stem cells are abnormal in multiple myeloma. Leukemia 2007; 21: 1079-1088.

5 Dispenzieri A. An internationally recognized uniform cytogenetic classification system is needed for multiple myeloma. Leukemia 2007; 20: 2034-2040.

6 Rabin N, Kyriakou C, Coulton L, Gallagher OM, Buckle C, Benjamin R et al. A new xenograft model of myeloma bone disease demonstrating the efficacy of human mesenchymal stem cells expressing osteoprotegerin by lentiviral gene transfer. Leukemia 2007; 21: 2181-2191.

7 Kyle RA, Therneau TM, Rajkumar SV, Larson DR, Plevak MF, Offord JR et al. Prevalence of monoclonal gammopathy of undetermined significance. N Engl J Med 2006; 35: 1362-1369.

8 Jego G, Bataille R, Geffroy-Luseau A, Descamps G, PellatDeceunynck C. Pathogen-associated molecular patterns are growth and survival factors for human myeloma cells through Toll-like receptors. Leukemia 2006; 20: 1130-1137.

9 Bohnhorst J, Rasmussen T, Moen SH, Flottum M, Knudsen L, Borset $\mathrm{M}$ et al. Toll-like receptors mediate proliferation and survival of multiple myeloma cells. Leukemia 2006; 20: 1138-1144.

10 Mantovani A, Garlanda C. Inflammation and multiple myeloma: the Toll connection. Leukemia 2006; 20: 937-938.

11 Bergsagel PL, Chesi M, Nardini E, Brents LA, Kirby SL, Kuehl WM. Promiscuous translocations into immunoglobulin heavy chain switch regions in multiple myeloma. Proc Natl Acad Sci USA 1996; 93: 13931-13936.

12 Fonseca R, Barlogie B, Bataille R, Bastard C, Bergsagel PL, Chesi M et al. Genetics and cytogenetics of multiple myeloma: a workshop report. Cancer Res 2004; 64: 1546-1558. 
13 Kyle RA, Therneau TM, Rajkumar SV, Offord JR, Larson DR, Plevak MF et al. A long-term study of prognosis of monoclonal gammopathy of undetermined significance. N Engl J Med 2002; 346: $564-569$

14 Tian E, Zhan F, Walker R, Rasmussen E, Ma Y, Barlogie B et al. The role of the Wnt-signaling antagonist DKK1 in the development of osteolytic lesions in multiple myeloma. N Engl J Med 2003; 349: 2483-2494.

15 Singhal S, Mehta J, Desikan R, Ayers D, Roberson P, Eddlemon P et al. Antitumor activity of thalidomide in refractory multiple myeloma. N Engl J Med 1999; 341: 1565-1571.

16 Richardson PG, Barlogie B, Berenson J, Singhal S, Jagannath S, Irwin $\mathrm{D}$ et al. A phase 2 study of bortezomib in relapsed, refractory myeloma. N Engl J Med 2003; 348: 2609-2617.

17 Richardson PG, Sonneveld P, Schuster MW, Irwin D, Stadtmauer $\mathrm{EA}$, Facon $\mathrm{T}$ et al. Bortezomib or high-dose dexamethasone for relapsed multiple myeloma. N Engl J Med 2005; 352: 2487-2498.

18 Cavo M. Proteasome inhibitor bortezomib for the treatment of multiple myeloma. Leukemia 2006; 20: 1341-1352.

19 Rajkumar SV, Hayman SR, Lacy MQ, Dispenzieri A, Geyer SM, Kabat B et al. Combination therapy with lenalidomide plus dexamethasone (Rev/Dex) for newly diagnosed myeloma. Blood 2005; 106: 4050-4053.

20 Richardson PG, Blood E, Mitsiades CS, Jagannath S, Zeldenrust SR, Alsina $M$ et al. A randomized phase 2 study of lenalidomide therapy for patients with relapsed or relapsed and refractory multiple myeloma. Blood 2006; 108: 3458-3464.

21 Mihelic R, Kaufman JL, Lonial S. Maintenance therapy in multiple myeloma. Leukemia 2007; 21: 1150-1157.

22 Sagaster V, Ludwig H, Kaufmann H, Odelga V, Zojer N, Ackermann $\mathrm{J}$ et al. Bortezomib in relapsed multiple myeloma: response rates and duration of response are independent of a chromosome 13q-deletion. Leukemia 2007; 21: 164-168.

23 Stewart AK, Bergsagel PL, Greipp PR, Dispenzieri A, Gertz MA, Hayman SR et al. A practical guide to defining high-risk myeloma for clinical trials, patient counseling and choice of therapy. Leukemia 2007; 21: 529-534.

24 Stewart AK, Chang H, Trudel S, Anderson KC, Richardson P, Alsina $M$ et al. Diagnostic evaluation of $t(4 ; 14)$ in multiple myeloma and evidence for clonal evolution. Leukemia 2007; 21: 2358-2359.

25 Moreau P, Attal M, Garban F, Hulin C, Facon T, Marit G et al. Heterogeneity of $\mathrm{t}(4 ; 14)$ in multiple myeloma. Long-term followup of 100 cases treated with tandem transplantation in IFM99 trials. Leukemia 2007; 21: 2020-2024.

26 Fonseca R, Van Wier SA, Chng WJ, Ketterling R, Lacy MQ, Dispenzieri $A$ et al. Prognostic value of chromosome $1 \mathrm{q} 21$ gain by fluorescent in situ hybridization and increase CKS1B expression in myeloma. Leukemia 2006; 20: 2034-2040.

27 Chiecchio L, Protheroe RKM, Ibrahim AH, Cheung KL, Rudduck C, Dagrada GP et al. Deletion of chromosome 13 detected by conventional cytogenetics is a critical prognostic factor in myeloma. Leukemia 2006; 20: 1610-1617.

28 Zhan F, Sawyer J, Tricot G. The role of cytogenetics in myeloma. Leukemia 2006; 20: 1484-1486.

29 San-Miguel J, Harousseau JL, Joshua D, Anderson KC. Individualizing treatment of patients with myeloma in the era of novel agents. J Clin Oncol 2008; 26: 2761-2766.

30 Durie BGM, Harousseau J-L, Miguel JS, Blade J, Barlogie B, Anderson $\mathrm{K}$ et al. International uniform response criteria for multiple myeloma. Leukemia 2006; 20: 1467-1473.

31 Dimopoulos MA, Kastritis E, Rosinol L, Bladé J, Ludwig $H$. Pathogenesis and treatment of renal failure in multiple myeloma. Leukemia 2008; 22: 1485-1493.

32 Dimopoulos MA, Kastritis E, Rajkumar SV. Treatment of plasma cell dyscrasias with lenalidomide. Leukemia 2008; 22: 1343-1353.

33 Bladé J, Rosiñol L, Cibeira MT, de Larrea CF. Pathogenesis and progression of monoclonal gammopathy of undetermined significance. Leukemia 2008; 22: 1651-1657.

34 Kyle RA, Rajkumar SV. Criteria for diagnosis, staging, risk stratification and response assessment of multiple myeloma. Leukemia 2009; 23: 3-9.

35 Podar K, Chauhan D, Anderson KC. Bone marrow microenvironment and the identification of new targets for myeloma therapy. Leukemia 2009; 23: 10-24.

36 Palumbo A, Rajkumar SV. Treatment of newly diagnosed myeloma. Leukemia 2009; 23: 449-456.

37 Bensinger WI. Role of autologous and allogeneic stem cell transplantation in myeloma. Leukemia 2009; 23: 442-448.

38 Dispenzieri A, Kyle R, Merlini G, Miguel JS, Ludwig H, Hajek R et al. International Myeloma Working Group guidelines for serumfree light chain analysis in multiple myeloma and related disorders. Leukemia 2009; 23: 215-224.

39 Roodman GD. Pathogenesis of myeloma bone disease. Leukemia 2009; 23: 435-441.

40 Landgren $\mathrm{O}$, Weiss BM. Patterns of monoclonal gammopathy of undetermined significance and multiple myeloma in various ethnic/racial groups: support for genetic factors in pathogenesis. Leukemia 2009; 23: 1691-1697.

41 Zhou Y, Barlogie B, Shaughnessy Jr JD. The molecular characterization and clinical management of multiple myeloma in the postgenome era. Leukemia 2009; 23: 1941-1956.

42 Laubach JP, Mahindra A, Mitsiades CS, Schlossman RL, Munshi NC, Ghobrial IM et al. The use of novel agents in the treatment of relapsed and refractory multiple myeloma. Leukemia 2009; 23: 2222-2232.

43 Shah JJ, Orlowski RZ. Proteasome inhibitors in the treatment of multiple myeloma. Leukemia 2009; 23: 1964-1979.

44 Fonseca R, Bergsagel PL, Drach J, Shaughnessy J, Gutierrez N, Stewart AK et al. International Myeloma Working Group molecular classification of multiple myeloma: spotlight review. Leukemia 2009; 23: 2210-2221. 